\title{
Segmented Eosinophil Count
}

National Cancer Institute

\section{Source}

National Cancer Institute. Segmented Eosinophil Count. NCI Thesaurus. Code C135412.

The determination of the amount of segmented eosinophils present in a sample. 